\title{
Expression of Hormone Receptor and Human Epidermal Growth Factor Receptor (HER2/neu) Status of Breast Carcinoma and Their Correlation with Clinico-Pathological Parameters
}

\author{
Bushra Sikandar $^{1}$, Yusra Shafique ${ }^{1 *}$, Uzma Bukhari ${ }^{1}$ and Sidra Memon ${ }^{2}$ \\ ${ }^{1}$ Department of Pathology, Dow Medical College, Pakistan \\ ${ }^{2}$ Department of Surgery, Dow Medical College, Pakistan
}

*Corresponding author: Yusra Shafique, Department of Pathology, $2^{\text {nd }}$ floor, Dow Medical College, Dow University of Health

Sciences, Karachi, Sindh, Pakistan

\section{ARTICLE INFO}

Received: 㗀 January 20, 2020

Published: 㓞 February 03, 2020

Citation: Bushra Sikandar, Yusra Shafique, Uzma Bukhari, Sidra Memon. Expression of Hormone Receptor and Human Epidermal Growth Factor Receptor (HER2/neu) Status of Breast Carcinoma and Their Correlation with Clinico-Pathological Parameters. Biomed J Sci \& Tech Res 25(2)-2020. BJSTR. MS.ID.004173.

Keywords: Breast Cancer; Estrogen Receptor; Progesterone Receptor; HER 2/ neu

\section{ABSTRACT}

Objectives: To investigate, the expression profiling of ER, PgR and HER2/neu in breast cancer cases of tertiary care hospital and to correlate the hormone receptors and HER2/neu expression with clinico-pathological parameters.

Design: Case series study

Setting: Histopathology section of Dow Diagnostic Research and Reference Laboratory, (DDRRL) Karachi

Methodology: A total of 104 mastectomy samples were collected retrospectively between January 2018 to August 2019 at Histopathology section of Dow Diagnostic Research and Reference Laboratory, (DDRRL) Karachi. Clinico-pathological parameters of tumors were recorded, and receptor status was evaluated by immunohistochemistry using $\alpha$-ER, $\alpha$-PgR and $\alpha$-HER2/neu antibodies. SPSS version 21 was used. Result analysis was done by using Chi-square and Fisher's exact tests. A p-value of $<0.05$ was considered as statistically significant.

Results: Of the 104 patients in our study, a total of $06(5.7 \%)$ were diagnosed as IDC-I, $76(73 \%)$ as IDC-II and $22(21 \%)$ as IDC-III patients. A total of $27(25 \%)$ patients had triple negative tumors (ER-, PR-, Her2-), 16 (15\%) patients had tumors expressing Her2 only, 37 (35.5\%) had tumors with ER and PgR expression and 24 had tumors with ER, PgR and Her2/neu expression. The grade of the tumor was significantly correlated to hormone expression of ER and PgR, whereas no significant correlation of grade was noted with HER2/neu.

Conclusion: Our data demonstrate alarming findings in breast cancer patients from Pakistan i.e, increased triple negative tumors along with increased number of patients with poor prognosis at clinical presentation and early onset of breast cancer in Pakistani patient. This provides valuable prognostic information in order to decide the therapeutic options in patients.

\section{Article Summary}

Article Focus: This study evaluates the expression of ER, PgR, Her2/neu and correlates their expression with cinico-pathological parameters. As due to increase frequency of breast cancer cases,

specifically triple negative cases, prompt diagnosis and evaluation of receptor status is the fundamental part for in order to precisely start the chemotherapeutic options. Moreover, other clinic- 
pathological parameters are critically decisive in correlating the prognosis of the patient and aiding in planning the strategies for targeted treatment options which is relevant for individual patient.

Key Message: Breast cancer is the most common tumor in females across the pocket of the globe. The diagnosis and prognosis of breast cancer depends on hormone receptor and HER2/neu status. The expression of these receptors and clinic pathologic parameters differ in various ethnic population of world. In this context, it becomes highly relevant to investigate tumor biology in our population in order to devise appropriate diagnostic, therapeutic and prognostic approaches.

\section{Strengths and limitations of Study}

a) Our study suggests, that in Pakistan, there is increase frequency of triple negative breast cancer which demands correlation with more parameters for predicting early prognosis and decision the strategic plan for further treatment option.

b) One of the limitations is we did not use Fluorescence hybridization in situ (FISH) assay in order to further re-evaluate HER 2/neu (+2 equivocal cases), due to budget/ resources and time constrain.

c) All cases are of invasive ducal carcinoma, a subtype of breast cancer, other subtypes are excluded in the study.

\section{Introduction}

Breast cancer is the second most common cancer amongst all cancers and fifth major cause of cancer associated deaths globally [1]. In year 2018, 2.1 million new cases of breast cancer were reported out of 18.1 million cases worldwide. In Pakistan breast cancer ranks the first most common cancer with $19.6 \%$ of all new cancers reported and first most common cause of cancer associated deaths with $14.5 \%$ mortality [1-3]. Interestingly, tumor biology as well as clinico-pathological features of breast carcinogenesis follow varying footprints in different geographical pockets of the globe $[4,5]$. For example, contrary to the Western countries where breast cancer is common in 60-70 years of age, in Pakistan it is more common in a younger age group (mean age of breast cancer diagnosis is 40-50 years) [5,6]. Moreover, expression patterns of estrogen receptor (ER), progesterone receptor (PgR) and HER2/ neu differs substantially in different ethnic groups across the world $[7,8]$. In this context, it becomes highly relevant to investigate tumor biology in various ethnic populations in order to devise appropriate diagnostic, therapeutic and prognostic approaches.

A major challenge while classifying breasttumors is to adapt such a classification system that accurately predicts/depicts patient's prognosis. In this attempt, various prognostic factors have been used that anticipate the outcome of patient in absence of systemic therapy, estimate the outcome of systemic therapy and also act as predictive factors [9]. This includes the more conventionally used tumor grading system $[10,11]$ and a relatively neoteric algorithm, the Nottingham Prognostic Index (NPI), which is calculated using tumor grade, tumor size and lymph node metastasis [12-14]. More recently, expression patterns of ER, PgR and HER2/neu expression is also detrimental in starting the anti-Her2 therapy (Herceptin). Globally, ER expression is reported in $75 \%$, PgR expression in $65 \%$ and HER2/neu expression in $20-25 \%$ of breast tumours $[11,15,16]$. Expression of ER and PgR denotes a favorable prognosis while HER $2 /$ neu expression is considered as a marker of tumor aggression $[11,17]$. The worst prognostic group however is triple negative/ basal like (ER-, PgR-, Her2/neu-) breast tumors, which accounts for $15 \%$ of breast tumors globally [18]. Data regarding expression patterns of ER, PgR and HER2/neu in breast cancer from Pakistani patients is scanty and therefore demands active investigation. In this study, breast cancer patients were investigated for various clinico-pathological parameters as well as ER, PgR and HER 2/neu expression status.

\section{Materials and Methods}

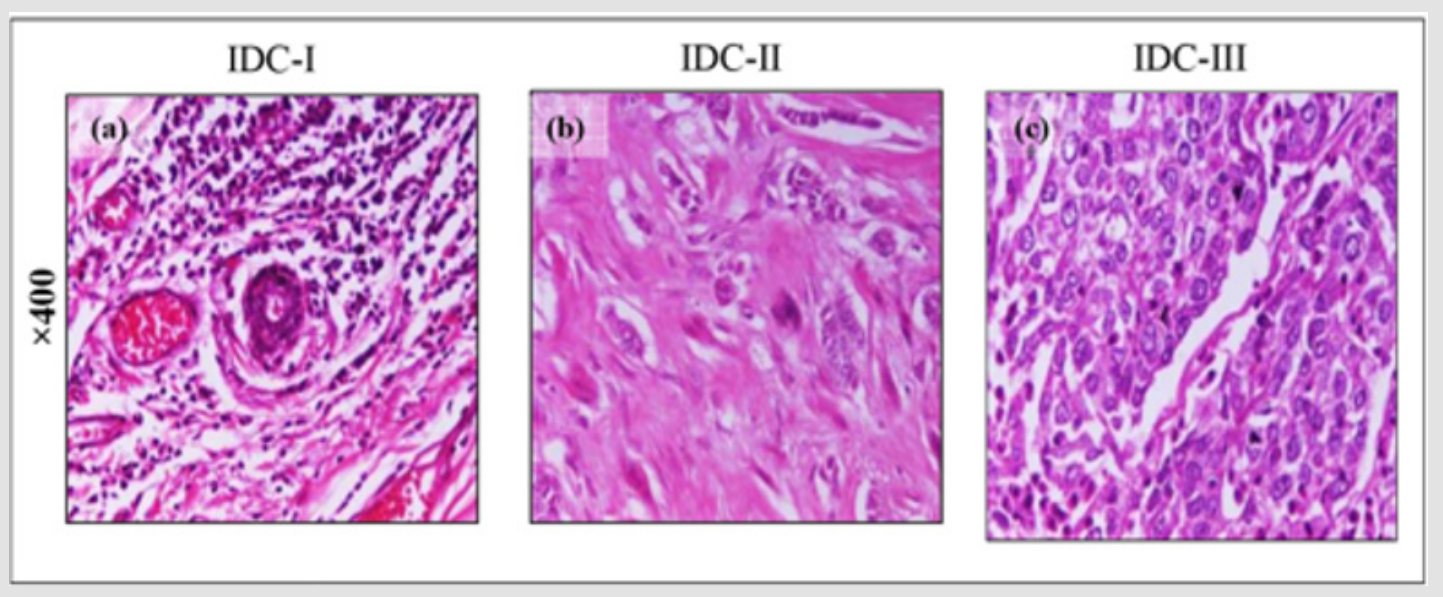

Figure 1: Formalin fixed tissue sections from breast cancer patients stained with Haematoxylin and Eosin. Microphotographs of H\&E of Infiltrating Ductal Carcinoma at original magnification at $x 40$ are shown (a) IDC-I (b) IDC-II (c) IDC-III. 
The study was conducted at the Dow University of Health Sciences (DUHS) Karachi after ethical approval (Ref \# IRB-460/ DUHS/14). A total of 104 mastectomy specimens (with lymph node dissections) from January 2019 to August 2019 were recruited in the study. Breast tumors and lymph nodes resected during the surgery were transported to the Histopathology section of the Dow diagnostic research and reference laboratory in 10\% neutral buffered formalin. Clinico-pathological data were recorded for age, tumor size, tumor grade, presence (or absence) of DCIS component, lymph node status (LN) and lympho-vascular invasion
(LV) of tumor. In order to investigate tumor morphology, grading and subtyping, $\mathrm{H} \& \mathrm{E}$ staining was performed (Figure 1). Receptor status was investigated using antibodies against ER, PgR and HER2/ neu. ER and PgR scores were calculated using the Allred scoring system $[10,15]$ while HER2/neu staining was scored using the WHO guidelines [7] (Figure 2). Moreover, patients were classified into various prognostic groups using the NPI scoring system. Data were entered in SPSS version 21 and correlations were investigated using Chi-square and Fisher's exact test. A p-value of $<0.05$ was consider as statistically significant.

(A)

(B)

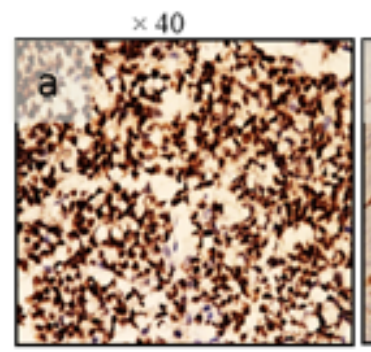

ER

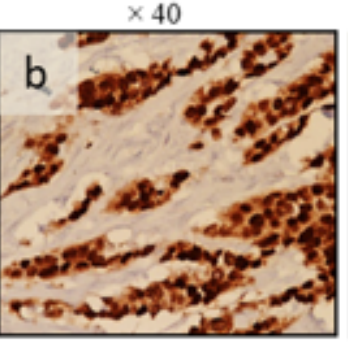

$\mathrm{PgR}$ $\times 40$

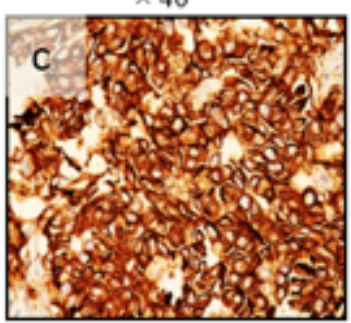

HER 2/neu

\begin{tabular}{|c|c|c|c|}
\hline \multicolumn{2}{|c|}{$\begin{array}{c}\text { Proportion of ER and PgR } \\
\text { positive cells }\end{array}$} & \multicolumn{2}{c|}{$\begin{array}{c}\text { Intensity of ER and PgR } \\
\text { positive cells }\end{array}$} \\
\hline $\begin{array}{c}\text { Proportion score } \\
\text { (PS) }\end{array}$ & $\%$ f positive cells & $\begin{array}{c}\text { Intensity Score } \\
\text { (IS) }\end{array}$ & Intensity of Positivity \\
\hline 0 & 0 & 0 & None \\
\hline 1 & $<1 \%$ & 1 & Weak \\
\hline 2 & $1 \%$ to $10 \%$ & 2 & Intermediate \\
\hline 3 & $11 \%$ to $33 \%$ & 3 & Strong \\
\hline 4 & $34 \%$ to $66 \%$ & & \\
\hline 5 & $>67 \%$ & & \\
\hline
\end{tabular}

Total score $=$ PS + IS

$0-2=$ Negative for $E R, P g R$

3-8= Positive for $E R$ and $\mathrm{PgR}$

(C)

\begin{tabular}{|c|c|}
\hline \multicolumn{2}{|c|}{ Her2 protein detection on tumor cell } \\
\hline $\begin{array}{l}\text { IHC score } \\
\text { of Her } 2\end{array}$ & Criteria \\
\hline $\begin{array}{c}0 \\
\text { (Negative) }\end{array}$ & No immune reactivity or positive in $<10 \%$ of tumor cells. \\
\hline $\begin{array}{c}1+ \\
\text { (Negative) }\end{array}$ & $\begin{array}{c}\text { Weak immune reactivity in }>10 \% \text { of tumor cells but only } \\
\text { portion of membrane is positive }\end{array}$ \\
\hline $\begin{array}{c}2+ \\
\text { (equivocal) }\end{array}$ & $\begin{array}{l}\text { Weak to moderate complete membrane positivity in }>10 \% \text { of } \\
\text { cells or circumferential staining in } \leq 30 \% \text { of cells }\end{array}$ \\
\hline $3+$ (Positive) & $\begin{array}{c}\text { More than } 30 \% \text { of tumor cells must show circum ferential } \\
\text { intense n uniform membrane staining }\end{array}$ \\
\hline
\end{tabular}

Figure 2: (A) Formalin fixed tissue sections from breast cancer patients stained with (a)a-ER, (b) a-PgR and (c) a-HER 2/neu antibodies at $\times 40$ magnification (B) Quantification of ER, PgR by Allred scoring. (C) Reporting criteria for quantification of HER2/neu status by IHC.

\section{Patient and Public Involvement:}

No Patients were involved in the study. The study was conducted on histopathology tissue blocks of the cases and the results for ER, PgR and HER2/neu was informed to the patients through histopathological reports.

\section{Results}

\section{Clinico-Pathological Features of Breast Cancer Patients}

Mean age of breast cancer patients recruited in the study was 47 years. Of the 104 breast cancers that were investigated, a total 
of $9(8.7 \%)$ were $\leq 2 \mathrm{~cm}, 56(53.8 \%)$ were $2-5 \mathrm{~cm}$ and $39(37.5)$ were $>5 \mathrm{~cm}$ in size (Table 1). Histologically, $06(6 \%)$ tumors were IDC-I, $76(73 \%)$ were IDC-II and 22 (21\%) were IDC-III. DCIS component was absent in a total of $73(70.1 \%)$ tumors, $<5 \%$ in $14(13.5 \%)$ tumors, $5-10 \%$ in 13 (12.5\%) tumors and $>10 \%$ in 4 (3.9\%) tumors. Examination of lymph nodes resected during mastectomy showed that $38(36.5 \%)$ tumors did not metastasize to local lymph nodes, 23 (22.1\%) tumors involved 1-3 lymph nodes and 43 (41.4\%) tumors involved $>3$ lymph nodes. Lympho-vascular invasion (LV) of tumor cells was seen in a total of 42 (40\%) patients while 62 (59\%) patients were negative for LV invasion (Table 1).

Table 1: Clinico-pathological parameters of breast cancer tissues $(\mathrm{n}=104)$.

\begin{tabular}{|c|c|}
\hline Parameter & N (\%) \\
\hline Tumor size & \\
\hline$<2 \mathrm{~cm}$ & $9(8.7 \%)$ \\
\hline $2-5 \mathrm{~cm}$ & $56(53.8 \%)$ \\
\hline$>5 \mathrm{~cm}$ & $39(37.5 \%)$ \\
\hline DCIS component & \\
\hline$<5 \%$ & $14(13.5 \%)$ \\
\hline $5-10 \%$ & $13(12.5 \%)$ \\
\hline
\end{tabular}

\begin{tabular}{|c|c|}
\hline$>10 \%$ & $4(3.9 \%)$ \\
\hline Absent & $73(70.1 \%)$ \\
\hline LN status & \\
\hline Negative (0) & $38(36.5 \%)$ \\
\hline Positive (1-3) & $23(22.1 \%)$ \\
\hline Positive (>3) & $43(41.4 \%)$ \\
\hline LV invasion & \\
\hline Present & $42(40 \%)$ \\
\hline Absent & $62(59 \%)$ \\
\hline
\end{tabular}

\section{ER, PgR and HER2/neu Expression in Breast Cancers}

Of the 104 cancers that we investigated, a total of $27(25 \%)$ were triple negative (ER-, PgR-, HER2/neu), 16 (15\%) showed only HER2/neu expression, 37 (35.5\%) were Luminal A (ER+ and PgR+) and 24 (23\%) were Luminal B (ER+, PgR+, HER2/neu+). Triple negative cases as well as ER, PgR positive tumors were most common in the patients aged 40-49 years (Figure 3 ). Tumors which were positive only for HER2/neu were most common in patients aged 50-59 years while Luminal B cases (ER+, PgR+ and HER2/ neu+) were almost equally distributed across the age bracket of 30 59 years.

(A) Age distribution of cases according to ER, PgR \& Her2 expression
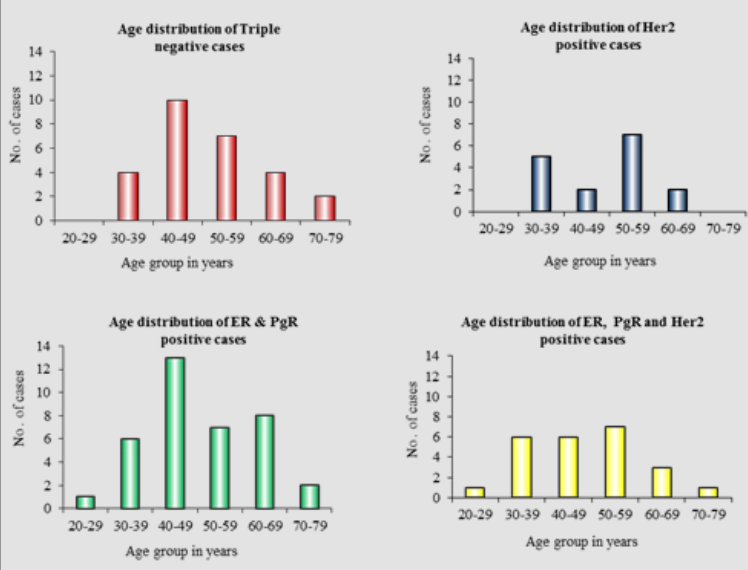

Age group in years

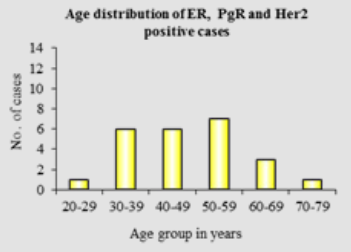

(B) NPI score distribution according to ER, PgR and Her2 expression

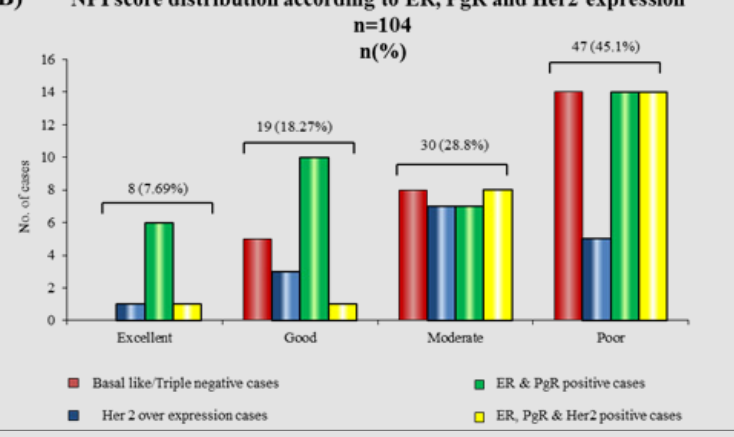

Figure 3: Distribution of ER, PgR and HER2 expression according to age and NPI score. (A) Distribution of age in years according to receptor status of breast cancer. (B) Distribution of receptor status in different NPI based prognostic sub- groups. $\mathrm{ER}=$ estrogen receptor; $\mathrm{PgR}=$ progesterone receptor; HER2= human epidermal growth factor receptor; NPI=Nottingham prognostic index. 


\section{NPI classification of breast tumors and patient prognosis}

The NPI scoring of tumors showed a total of 47 (45.1\%) patients with poor, 19 (18.27\%) with good, 30 (28.8\%) with moderate and 8 (7.69\%) with excellent prognosis tumors (Figure 3).

\section{Correlation of ER, PgR and Her2 expression with clin- ic-pathological parameters and NPI scores}

Expression of ER and PgR correlated significantly with tumor grades (Table 2). IDC-I and IDC-II tumours were by-enlarge ER and PgR positive, whereas majority of IDC III tumors were ER and PgR negative. HER2/neu expression did not correlate significantly with tumor grades. Moreover, no significant association was noted between ER, PgR, HER2/neu expression between tumor size and lymph node status (Table 2). We also correlated ER, PgR and HER2/neu expression with different prognostic groups (as per NPI scoring). Of the $37 \mathrm{ER}, \mathrm{PgR}$ positive tumors a total of 14 were poor, 10 were good, 7 were moderate and 6 were excellent prognostic tumors. Of the 16 tumors that expressed only HER2/neu a total of 5 were poor, 3 were good, 7 were moderate and 1 were excellent prognostic tumors. Of the $27 \mathrm{basal} /$ triple negative tumors, a total of 14 were poor, 5 were good, 8 were moderate and 0 were excellent prognostic tumors.

Table 2: Correlation of ER, PgR and HER2/neu with different parameters.

\begin{tabular}{|c|c|c|c|c|c|c|}
\hline \multirow{2}{*}{ Parameters } & \multicolumn{2}{|c|}{ ER status } & \multicolumn{2}{|c|}{ PgR status } & \multicolumn{2}{|c|}{ HER2/neu status } \\
\hline & Positive & Negative & Positive & Negative & Positive & Negative \\
\hline \multicolumn{7}{|l|}{ Tumor Size } \\
\hline$<2 \mathrm{~cm}$ & 6 & 3 & 6 & 3 & 5 & 3 \\
\hline $2-5 \mathrm{~cm}$ & 33 & 23 & 31 & 25 & 20 & 36 \\
\hline \multirow[t]{2}{*}{$>5 \mathrm{~cm}$} & 19 & 20 & 15 & 24 & 15 & 24 \\
\hline & $\mathbf{p}=$ & 0.485 & $\mathbf{p}=$ & 0.156 & $\mathbf{p}=$ & 0.347 \\
\hline \multicolumn{7}{|l|}{ Tumor Grade } \\
\hline IDC-I & 5 & 1 & 5 & 1 & 2 & 4 \\
\hline IDC-II & 48 & 28 & 43 & 33 & 29 & 46 \\
\hline \multirow[t]{2}{*}{ IDC-III } & 5 & 17 & 4 & 18 & 9 & 13 \\
\hline & $\mathbf{p}=$ & 0.001 & $\mathbf{p}=$ & 0.002 & $\mathbf{p}=$ & 0.943 \\
\hline \multicolumn{7}{|l|}{ Nodal Status } \\
\hline 0 & 21 & 17 & 19 & 19 & 13 & 24 \\
\hline $1-3$ & 14 & 9 & 12 & 11 & 9 & 14 \\
\hline \multirow[t]{2}{*}{$>3$} & 23 & 20 & 21 & 22 & 18 & 25 \\
\hline & $p=0.845$ & $p=0.967$ & $p=0.827$ & & & \\
\hline
\end{tabular}

\section{Discussion}

Breast tumor is the most common malignancy in females and its prognosis depends on many clinic pathologic parameters like age, histologic type, grade, lymph node status, tumor size and receptor status, the last being the most important prognostic marker as it effects the 5 year survival rate, mortality rate and disease free survival [19]. Breast cancer biology and the associated clinicopathological features show varied patterns in various parts of the world - probably due to varying genetic and environmental factors [4-6]. It is therefore extremely important to investigate breast cancer biology in geographically distinct populations in order to better understand the underlying carcinogenic mechanisms/events and to improvise the currently available diagnostic, therapeutic and prognostic approach. Alarmingly, our data show a total of 27 $(25 \%)$ patients with triple negative cancers (ER,PgR-, HER2/neu-) and most of these patients were 40-50 years of age. These data are in agreement with the literature which reports increased number of triple negative breast cancers in African patients at younger age compared to the patients in western countries, where $15 \%$ of the cancers are triple negative [7,8,16-19].
Moreover, data from other Asian countries including China, India, Malaysia and Indonesia, demonstrate that Asian females usually present to the clinics with higher tumor grade compared to the Western world $[20,21]$. Patients with triple negative and poor prognosis tumors are challenging to manage as there are illdefined therapeutic options available [22,23]. Increased number of triple negative tumors and tumors with poor prognosis (as per the NPI scoring), particularly at an early age, in Pakistani population is therefore an alarming finding that needs to be reported and addressed accordingly. In our study, majority of the low-grade tumors (IDC-I and IDC-II) expressed ER and PgR while majority of the high grade tumors (IDC-III) did not express these receptors. These findings are in line with the available literature where ER and PgR expression has been linked to a better prognosis (and lower tumor grades). Intriguingly, we did not see any correlation between HER2/neu expression and tumor grades, tumor size and lymph node status. This finding is in stark contrast to several reports where HER2/neu expression has been significantly correlated with tumor size, higher grade and positive LN status [14,24,25]. However, use of IHC in order to assess HER2/neu expression itself is 
a debatable issue. Therefore, it would have been more confirmatory if these samples could also be investigated using Flourescent insitu hybridization (FISH). Taken together, we highlight alarming findings in breast cancer patients from Pakistan i.e, increased triple negative tumors, patients with poor prognosis at the time of clinical presentation and early onset of breast tumors that demand further investigation.

\section{Key message}

Breast cancer is the most common tumor in females globally and ranks as first in our country Pakistan. The diagnosis and prognosis of breast cancer depends on hormone receptor and HER2/neu status. The expression of these receptors and clinic pathologic parameters differ in various ethnic population of world. In this context, it becomes highly relevant to investigate tumor biology in our population in order to devise appropriate diagnostic, therapeutic and prognostic approaches. Our study suggests that in Pakistan there is increased number of triple negative tumors and most patients present at the time of poor prognosis, so this demands further investigation.

\section{Author contribution}

Dr. Bushra Sikandar: Substantial contributions to conception and design, Acquisition of data, analysis and interpretation of data, Drafting the article, Revision of article for important intellectual content, final approval of version to be published. Dr Yusra Shafique: Substantial contributions to conception and design, Acquisition of data, analysis and interpretation of data, Drafting the article, Revision of article for important intellectual content, final approval of version to be published. Dr. Uzma Bukhari: Revision of article for important intellectual content, final approval of version to be published. Dr. Sidra Memon: Revision of article for important intellectual content, final approval of version to be published.

\section{Funding}

Self-funded.

\section{Conflicts of Interest}

None.

\section{Ethics Approval}

Ethics approval was provided by Institutional Review Board.

\section{Provenance and Peer review}

Not commissioned.

\section{Data Sharing Statement}

There are no additional data available.

\section{References}

1. Bray F, Ferlay J, Soerjomataram I, Siegel RL, Torre LA, et al. (2018) Global cancer statistics 2018: GLOBOCAN estimates of incidence and mortality worldwide for 36 cancers in 185 countries. CA: a cancer journal for clinicians 68(6): 394-424.
2. Ferlay J, Soerjomataram I, Ervik M, Dikshit R, Eser S, et al. (2016) GLOBOCAN 2012 v1. 0, cancer incidence and mortality worldwide: IARC CancerBase No. 11. Lyon, France: International agency for research on cancer.

3. Sarwar MR, Saqib A (2017) Cancer prevalence, incidence and mortality rates in Pakistan in 2012. Cogent Medicine 4(1): 1288773.

4. Formenti SC AA, Love SM (2012) Global Breast Cancer: The Lessons to Bring Home. International journal of breast cancer.

5. Seyed Houssein Mousavi Jarrrahi, Amir Kasaeian, Kamyar Mansori, Mehdi Ranjbaran, Mahmoud Khodadost, et al. (2013) Addressing the Younger Age at Onset in Breast Cancer Patients in Asia: An Age-PeriodCohort Analysis of Fifty Years of Quality Data from the International Agency for Research on Cancer. ISRN Oncology 2013: 429862.

6. Thiygarajan M, Navrathan N, Mohanapriya T, Kumar A, Singh B, et al. (2016) Correlation between estrogen receptor, progesterone receptor HER-2/neu status and other prognostic factors in carcinoma breast in Indian population. International Surgery Journal 2(4): 515-522.

7. Koyuncuer A (2018) Correlation of Her2 Status with hormone receptors estrogen, progesterone receptors and histopathologic features in invasive breast carcinomas: A study on 117 consecutive patients. Acta medica mediterranea 34(6): 1943-1948.

8. Amirikia KC, Mills P, Bush J, Newman LA (2011) Higher populationbased incidence rates of triple-negative breast cancer among young African American women: Implications for breast cancer screening recommendations. Cancer 117(12): 2747-2753.

9. Gamit A, Galani V, Vithlani N (2018) Analysis of Prognostic Factors in Early Stage and Locally Advanced Breast Cancer

10. GV (2012) The current state of breast cancer classification. Annals of Oncology. Annals of Oncology 27: 207-210.

11. (2014) Surgical Pathology Cancer Case Summary.

12. Galea MH BR, Elston CE, Ellis IO (1992) The Nottingham prognostic index in primary breast cancer. Breast cancer research and treatment 22: 207-209.

13. Rakha EA SD, Lemetre C, Green AR, Powe DG, Nolan CC, et al. (2014) Nottingham prognostic index plus (npi+): a modern clinical decisionmaking tool in breast. Br J Cancer 7: 1688-1697.

14. Onitilo AA EJ, Greenlee RT, Mukesh BN (2009) Breast cancer subtypes based on ER/PR and Her2 expression: comparison of clinicopathologic features and survival. Clin Med Res 7: 4-13.

15. Azam M, Qureshi Asim, Samina Mansoor (2009) Comparison of Estrogen receptors, Progesterone receptors and HER-2/neu Expression between Primary and Metastatic Breast Carcinoma. JPMA 59: 736-740.

16. Allred DC (2010) ASCO/CAP Guidline Recommendation for IHC Testing of ER and PgR in Breast Cancer. Arcg Pathol Lab Med 134: 907-922.

17. Goud KI, Dayakar Seetha, Vijayalaxmi K, Babu SJ, Reddy P VA (2012) Evaluation of HER2/neu status in breast cancer specimens using immunohistochemistry (IHC) \& fluorescence in-situ hybridization (FISH) assay. Indian J Med 135: 312-317.

18. (2015) Triple-Negative Breast Cancer.

19. Akbar A, Mudassir G, Abid M, Naveed H, Majeed M, et al. (2018) Correlation of Molecular Subtypes with Clinico Correlation of Molecular Subtypes with Clinico Correlation of Molecular Subtypes with Clinico Correlation of Molecular Subtypes with Clinico Correlation of Molecular Subtypes with Clinico Correlation of Molecu. Journal of Rawalpindi Medical College 3: 318-321.

20. Tasneem S, Naseer F, Shahid S, Nasreen S, Khan MM, et al. (2012) A study of prognostic markers and stage of presentation of reast cancer in southern region of khyber pakhtunkhwa, Pakistan 20: 63-66.

21. Kamil M, Khalid I, Hashim H, Biswas M, Kaur G, et al. (2012) Association of carcinoma breast: grade and estrogen progesterone receptor expression. J Coll Physicians Surg Pak 20(4): 250-252. 
22. Dent R, Trudeau M, Pritchard KI, Hanna WM, Kahn HK, et al. (2007) Triple negative breast cancer: clinical features and patterns of recurrence. Clin Cancer Res 13(15): 4429-4434.

23. Hudis CA, Gianni L (2011) Triple-negative breast cancer: an unmet medical need. Oncologist 16(1): 1-11.

24. Faheem M, Mahmeed H, Khurram M, Qasim U, Irfan J, et al. (2012) Estrogen receptor, progesterone receptor, and Her 2 Neu positivity and

ISSN: 2574-1241

DOI: 10.26717/BJSTR.2020.25.004173

Yusra Shafique. Biomed J Sci \& Tech Res

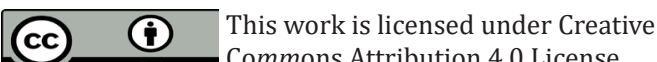

Submission Link: https://biomedres.us/submit-manuscript.php its association with tumour characteristics and menopausal status in a breast cancer cohort from northern Pakistan. Ecancer 6: 283-291.

25. Puri V, Jain M, Thomas Shaji (2011) Stromal Expression of CD10 in Invasive Breast Carcinoma and Its Correlation with ER, PR, HER2-neu and Ki67. International Journal of Breast Cancer 10: 4061-4065.

$\begin{array}{ll}\text { BIOMEDICAL } & \text { Assets of Publishing with us } \\ \text { RESEARCHES } & \text { - Global archiving of articles } \\ \text { - Immediate, unrestricted online access }\end{array}$

